\title{
Domestic violence: its relevance to psychiatry
}

\section{Louise M. Howard}

\begin{abstract}
SUMMARY
Domestic violence is a major public health problem because it is common and associated with physical and mental health morbidity. It is more common in psychiatric patients but is underdetected by mental health professionals. Routine enquiry increases detection but needs to be introduced in the context of comprehensive training, and only where referral and care pathways have been developed. High-risk patients should be referred to multi-agency risk assessment conferences for multidisciplinary assessment and safe management.

\section{DECLARATION OF INTEREST}

L. M. H. currently receives funding from a National Institute for Health Research (NIHR) Programme Grant for Applied Research on Improving the Healthcare Response to Domestic Violence.
\end{abstract}

Domestic violence is defined in the UK as 'any incident of threatening behaviour, violence or abuse (psychological, physical, sexual, financial or emotional) between adults who are or have been intimate partners or family members, regardless of gender or sexuality' (Home Office 2010). This definition applies to adult family members (above 17 years old). It encompasses traditional cultural practices, including forced marriage, so-called 'honour crimes' and female genital mutilation, in addition to partner violence. However, most research has been confined to partner violence.

There is no international consensus on which term to use for domestic violence and some believe that the term 'domestic violence' is misleading because 'domestic' implies that the violence occurs at home. Some international studies use the term 'intimate partner violence', but this implies an intimacy that partners may not share and assumes violence from the partner when other family members may be involved. In this article I use the term domestic violence, but will specify where studies refer to non-heterosexual partner violence or other family members.

\section{The prevalence of domestic violence}

Domestic violence is common. In the general population, the lifetime prevalence of isolated domestic violence incidents is comparable for men (one in five) and women (one in four), but women are at greater risk of repeated coercive, sexual or severe physical violence (Howard 2010a). For example, the British Crime Survey for England and Wales estimated that, in $2001,89 \%$ of people who experienced four or more domestic violence assaults were women (Walby 2004). The same survey estimated that $45 \%$ of women and $26 \%$ of men aged 16-59 had experienced at least one episode of interpersonal violence (using the broad definition above); if financial or emotional abuse are excluded, then $21 \%$ of women and $10 \%$ of men had experienced domestic violence since the age of 16 (Walby 2004).

Most prevalence studies have focused on female populations, owing to the higher risk of serious morbidity for female victims. The World Health Organization multicountry study reported that lifetime prevalence of physical or sexual partner violence, or both, varied from 15 to $71 \%$ among the countries studied, with two sites having a prevalence of less than $25 \%$, seven between 25 and 50\% and six between 50 and 75\% (Garcia-Moreno 2006). The study also found that between 4 and $54 \%$ of respondents reported physical or sexual partner violence, or both, in the past year. In all but one setting, women were at far greater risk of physical or sexual violence by a partner than from violence by other people. Alhabib et al (2010) conducted a systematic review of 134 international studies (published 1995-2006) measuring the prevalence of domestic violence among women (although they excluded pregnant women and those with disabilities). Mean lifetime prevalence rates for adulthood physical and sexual violence were found to be highest in studies conducted in healthcare settings, including psychiatric and obstetric/gynaecology settings.

\section{Repeated victimisation}

Victims of domestic violence are rarely subjected to just one form of abuse: around half of women experiencing domestic violence face more than one type of violence (Coleman 2007). Findings also suggest gender differences in repeated victimisation: male victims experience up to
Louise Howard is Professor in Women's Mental Health at the Institute of Psychiatry, King's College London and an honorary consultant psychiatrist at South London and Maudsley NHS Foundation Trust. Her main research interests are domestic violence, perinatal mental health and the physical health of people with mental illness. Professor Howard is affiliated with the National Institute for Health Research Specialist Biomedical Research Centre for Mental Health in London. Correspondence Professor Louise M. Howard, P031 Section of Women's Mental Health, Health Service and Population Research Department, Institute of Psychiatry, King's College London, De Crespigny Park, London SE5 8AF, UK. Email: louise.howard@kcl.ac.uk 
7 instances of repeated victimisation, female victims an average of 20 incidents (Walby 2004). Domestic violence has the highest rate of repeated victimisation of any violent crime (Howard 2010a); the psychological consequences of this repeated trauma are discussed below.

\section{Homosexual relationships}

Less is known about gender differences in male compared with female homosexual relationships, but a US survey found that rates of emotional and physical violence victimisation among urban men who have sex with men were substantially higher than previously reported among heterosexual men $-34 \%$ reported psychological violence, $22 \%$ physical violence, and $5 \%$ sexual violence (Greenwood 2002). Studies from the USA increasingly suggest that prevalence of domestic violence may be similar across same-sex and heterosexual relationships and what differs are help-seeking behaviours (Howard 2010a). In a UK survey of 800 homosexual men and women, Hester (2009) reported that more than a third of respondents (38\%) said that they had experienced domestic abuse at some time in a same-sex relationship, with similar proportions in women (40\%) and men (35\%). However, the main prevalence data on domestic violence worldwide are derived from surveys that do not identify individuals in same-sex relationships, so current knowledge on violence occurring in homosexual relationships in epidemiologically representative populations is limited.

\section{Domestic violence and physical and mental health}

A review of the impact of domestic violence on physical health is beyond the scope of this article but some of the most common sequelae include gynaecological problems, sexually transmitted diseases (including HIV/AIDS), physical injuries and functional symptoms such as headaches, irritable bowel syndrome and chronic pelvic pain (see Campbell 2002 for a comprehensive review). The most severe consequence of domestic violence is death; in England and Wales two women a week are killed by a partner or ex-partner (Povey 2004), with risk highest in the months after leaving the partner. Similar mortality rates have been found throughout the international literature. Worldwide, domestic violence is as serious a cause of death and incapacity among women aged 15-49 as cancer (Howard 2010a).

Domestic violence is associated with many mental health problems, including post-traumatic stress disorder (PTSD), depression, suicidal ideation, substance misuse, functional symptoms and exacerbation of psychotic symptoms (Howard 2010b). Ludermir (2010) estimated the population attributable fraction (PAF) for domestic violence associated with postnatal depression to be $10 \%$ in a Brazilian population. Population attributable fractions for other mental disorders have not yet been published but such calculations demonstrate that reducing the prevalence of domestic violence in our society could substantially reduce the burden of mental disorders and the great costs to health services. The cost of violence against women in England and Wales in 2008 has been estimated at $£ 1.7$ billion in healthcare costs plus an additional $£ 15.7$ billion in human and emotional cost (Walby 2009).

Domestic violence is more hidden and potentially more psychologically harmful than stranger violence because of the nature of the relationship between the perpetrator and victim. It has been shown to have deleterious psychological effects beyond other traumatic events; research comparing Israeli women who had experienced domestic violence against women victimised by other traumatic events found that $52 \%$ presented with significantly higher levels of PTSD and psychiatric symptomatology compared with those not reporting domestic violence (SharhabaniArzy 2003). Several studies have indicated that psychological violence can be as detrimental to mental health as physical violence (Jones 2001). Findings also indicate that women who are revictimised or who experience more than one form of abuse are at greater risk of mental illness and comorbidity (Jones 2001).

\section{Complex post-traumatic stress disorder}

The psychological effects of domestic violence can be conceptualised within a trauma framework, but the complex presentation of victims who have often been exposed to extensive control and repeated assaults may be more adequately captured with the concept of complex post-traumatic stress disorder (Herman 2001). Vulnerability to complex post-traumatic stress disorder in people experiencing domestic violence can also be related to a history of childhood abuse. Complex post-traumatic stress disorder extends beyond the classic cluster of intrusive, avoidance and arousal symptoms to incorporate changes in victims' attitudes about self, the perpetrator, relationships and beliefs. Symptoms include those of post-traumatic stress disorder with additional disturbance in affect regulation and interpersonal relationships (see associated features of post-traumatic stress disorder in the 
DSM-IV (American Psychiatric Association 1994), including: feelings of ineffectiveness, shame, despair or hopelessness; feeling permanently damaged; loss of previously sustained beliefs; hostility; social withdrawal; feeling constantly threatened; impaired relationships with others; or a change from the individual's previous personality characteristics).

\section{Mental illness and increased vulnerability}

Pre-existing mental health problems can also influence vulnerability to domestic violence. Serious mental illness increases the likelihood of being in unsafe environments and relationships, and vulnerability to violent victimisation (Khalifeh 2010). Analysis of prospective data has found that, in addition to the association between earlier histories of mental health disorders and subsequent entrapment in abusive relationships, women who are subjected to abusive relationships also have an increased risk of subsequent psychiatric morbidity (Howard 2010b). In addition, data from a systematic review (Golding 1999) found that rates of depression declined over time once the abuse had ceased and that the severity or duration of violence was associated with the prevalence or severity of depression. There is therefore evidence supporting a causal association between domestic violence and psychiatric disorders in both directions: psychiatric disorders can render a person more vulnerable to domestic violence, and domestic violence can damage mental health (Howard 2010b). A review found a history of severe domestic violence in at least $30 \%$ of psychiatric inpatients, with some studies reporting prevalence of more than 60\% (Howard 2010b), suggesting that being a victim of domestic violence is likely to be more prevalent in psychiatric patients than in the general population. A study of women in contact with community mental health teams in south London found that $60 \%$ had experienced domestic violence from partners (27\% during pregnancy) (Morgan 2010). It is not clear to what extent there are gender differences in the prevalence of domestic violence in patients with severe mental illness, but severe mental illnesses such as schizophrenia may increase the risk of being a victim of domestic violence for men as well as women (Khalifeh 2010).

\section{Risk factors for domestic violence}

Domestic violence occurs across all social classes, religions, ethnic groups and geographical areas, but there are certain risk factors associated with experiencing it. In addition to the gender differences described above, there is increasing evidence to show that the prevalence of domestic violence is higher among young women, those who are separated, or who have a history of childhood abuse or witnessing parental violence and poverty (Howard 2010a). There is also some evidence that domestic violence can start, or become more severe, in pregnancy (Gazmararian 2000). The Confidential Enquiry into Maternal Deaths (Lewis 2007), in its chapter on maternal deaths resulting from domestic violence, reports on a case where a woman with severe mental illness and a history of serious domestic violence was not provided with an appropriate package of care, did not attend antenatal appointments and was killed by her known violent partner. Migrant women may also be more vulnerable to abuse because of their isolation and that isolation will certainly affect their ability to access services. At the community level, domestic violence is more common in isolated communities and in those with high levels of violence, for example Palestinians exposed to political violence in the Palestinian territories (Howard 2010a).

\section{Identification of domestic violence experienced by psychiatric patients}

There is evidence that women are more likely to disclose domestic violence to a healthcare professional than to the police (women are assaulted an average of 35 times before they report domestic violence to the police; Yearnshire 1997). However, qualitative research in primary and secondary care has found that women may not disclose unless they are asked (Feder 2009; Rose 2011). Our review of identification in mental health services found that domestic violence is underdetected in services internationally, with only $10-30 \%$ of recent violence asked about and disclosed in clinical practice (Howard 2010b). Similar findings have been reported for primary care (Feder 2009).

A UK study found a number of common barriers to disclosure for psychiatric patients. The first is fear of the consequences: fear of Social Services involvement and consequent child protection proceedings; fear that disclosure would not be believed; and fear that disclosure would lead to further violence. Other barriers included the hidden nature of the violence, actions of the perpetrator (such as always being present when the victim is seen by health professionals) and feelings of shame. The main barriers for professionals to routinely asking about domestic violence concerned role boundaries, competency and confidence. Enquiry and disclosure were facilitated by a supportive and trusting relationship between patient and professional (Rose 2011), confirming similar findings in other healthcare settings (Feder 2009). 


\section{Routine enquiry}

There is some evidence that when routine enquiry about domestic violence is introduced across mental health services, detection rates improve. But even then, formulations and management plans rarely include issues around domestic violence so do not include safety planning or trauma-focused therapy (Howard 2010b). Therefore, it is now health policy in England, and some parts of the USA and New Zealand, to routinely enquire about domestic violence in all mental health assessments in psychiatric care (Read 1998; Department of Health 2008). Routine enquiry refers to 'asking all people within certain parameters about the experience of domestic violence, regardless of whether or not there are signs of abuse, or whether domestic violence is suspected' (Department of Health 2000). However, there is not yet clear evidence that routine enquiry leads to improvements in morbidity and mortality (Feder 2009). In fact, it can have adverse consequences, particularly if the perpetrator finds out about the partner's disclosure, as was found in an evaluation of routine enquiry in maternity services (Bacchus 2009). Therefore, professionals need comprehensive training in how to enquire safely, with clarity on subsequent care pathways that should be developed in all mental health trusts.

In England, the Department of Health has recommended that a question about any past or current violence and abuse should be asked during assessments and care programme approach meetings (Department of Health 2008). However, disclosure of domestic violence is more likely if specific behaviour-based questions are used. Open questions can be asked initially about relationships and normalisation of the area of enquiry can also be helpful, but more specific questions about each type of abuse should also be asked (Boxes 1-4 contain examples). Such questions can only be asked if a patient is alone or with a professional interpreter (rather than a family member).

Although there is limited research evidence in this area, good clinical practice includes making accurate notes, carrying out a risk assessment (particularly regarding immediate safety and considering the need for emergency action and/or child protection procedures), prioritising safety planning, avoiding victim-blaming and discussing available options (Hegarty 2008). Information about domestic violence services should be given (e.g. the option of referral to a refuge for women at high risk of serious injury), but professionals need to check whether it is safe for the patient to take information home with them - there may be an escalation of violence if such information is seen
BOX 1 Introductory open questions

- Are you having any problems with your husband/ partner?

- We know that one in four women (and one in five men) experience domestic violence at some time in their life so I ask everyone if that has ever happened to them. Has that happened to you?

- Some women have these symptoms when they are experiencing abuse. Are you afraid of anyone at home?

- Sometimes partners use physical force. Is this happening to you?

- Have you felt humiliated or emotionally abused by your partner (or ex-partner)?

- Has your partner ever physically threatened or hurt you? Or have you been kicked, hit, slapped or otherwise physically hurt by your partner (or ex-partner)?

- In the past year have you been forced to have any kind of sexual activity by your partner (or ex-partner)?

by the perpetrator. Potential interventions are discussed below but local healthcare trust policies (on domestic violence and on safeguarding of children and vulnerable adults), care pathways and training should include information on what to do after disclosure (Department of Health 2010).

\section{Interventions for psychiatric patients experiencing domestic violence}

\section{Psychological interventions}

A systematic review found that a wide range of individual psychological interventions benefit women with depression and PTSD, including

\section{BOX 2 Questions about psychological abuse}

- Does anyone insult you, call you names or swear at you?

- Does anyone make it difficult for you to see friends/ family or leave the house?

- Does anyone act in a jealous way or keep track of where you go?

- Does anyone put you down, embarrass you or criticise you?

- Does anyone undermine your independence or try to make you feel small?

- Does anyone make you feel as if you have to walk on eggshells or as if you do nothing right?

- Does anyone order you around like a servant?

- Does anyone blame you for things that are not your fault?

- Does anyone control the money, make you ask for it or stop you earning? 
BOX 3 Questions about sexual abuse

- Do you ever feel that you have to have sex even though you don't want to?

- Have you felt forced into sex because of what your partner might do?

- Has your partner made you have sex or carried on when it was painful?

- Has your partner made you have oral or anal sex when you didn't want to?

- Has your partner used an object in a sexual way that you didn't like?

- Has your partner made you do things or perform sexual acts that you didn't like?

- Has your partner refused safe sex or to use birth control?

- Has your partner made you have sex with another person?

- Has your partner talked about sex or done things in a way you didn't like?

reduced depressive symptoms and post-traumatic stress symptoms and improved self-esteem (Feder 2009). In particular, two trials reported that cognitive-behavioural therapy (CBT) helped women with PTSD who were no longer experiencing violence (Feder 2009). The National Institute for Health and Clinical Excellence also recommends eye movement desensitisation and reprocessing (EMDR) for post-traumatic stress disorder (National Collaborating Centre for Mental Health 2005), but there has been little research into its efficacy for PTSD associated

BOX 4 Questions about physical abuse

- Has your partner shaken you or grabbed you roughly?

- Has your partner shoved you or made you fall?

- Has your partner slapped you or smacked you?

- Has your partner tried to hit you with something or used an object as a weapon?

- Has your partner punched you?

- Has your partner tried to choke you or put his hands round your throat?

- Has your partner pushed you against the wall or thrown you down?

- Has your partner pulled your hair?

- Has your partner burnt you or scalded you with something?

- Has your partner threatened you with a knife or gun?

- Has your partner hurt you while you were pregnant? with domestic violence. There are also studies of group psychological interventions that show improvement in psychological outcomes, although these have methodological limitations (Feder 2009). It is possible that for people with complex PTSD, modified forms of therapy are needed, for example, CBT augmented by training in emotion regulation, which has been found to be more effective than stand-alone CBT in treating patients with a history of childhood abuse (Cloitre 2010).

However, these findings cannot be extrapolated to women still in abusive relationships or to women with more severe psychiatric illnesses and in contact with mental health services. Only one small randomised controlled trial of traumafocused CBT for patients with severe mental illness was identified in our previous review (Howard 2010b), providing some preliminary evidence of effectiveness in treating comorbid PTSD in patients with a primary diagnosis of schizophrenia or major mood disorder. This study did not, however, specifically focus on trauma in the context of domestic violence. Research is also needed on the cost-effectiveness of domestic violence interventions and the effectiveness and cost-effectiveness of interventions focused on changing the behaviours of the perpetrator.

\section{Domestic violence sector interventions}

\section{Refuges}

There is an increasing body of evidence about the psychological consequences of domestic violence, but less is known about the efficacy of interventions or protective factors that might ameliorate victims' responses to traumatic events (Campbell 1997; Wathen 2003). The most widely used interventions for domestic violence concern access to refuges or shelters to escape abuse (Wathen 2003). Controlled trials of such interventions have not been conducted in the light of victims' safety concerns and the complexity of evaluating multifaceted individualised programmes, but there is some evidence for refuge resident satisfaction and decreases in violence, as well as reduction in depressive symptoms and increases in self-esteem (Campbell 1997).

\section{Advocacy}

Rather than levels of abuse per se, outcome measures are usually focused on social support, safety behaviours and use of community resources (Wathen 2003). Sullivan \& Bybee (1999) conducted a randomised controlled trial in the USA in which women who had spent at least one night in a shelter were randomly assigned to advocacy services for 10 weeks or no contact. Of more than 200 women 
followed up for 2 years after the intervention, women in the intervention arm reported a decrease in physical violence across time and less re-abuse compared with the control group. The intervention group also reported an improvement in social support, access to resources and quality of life, although no differences were detected in levels of depression or psychological abuse.

A systematic review by Feder et al (2009) found further evidence that advocacy-based interventions can reduce abuse, increase social support and quality of life, and lead to increased use of safety behaviours and community resources. However, there remains a lack of studies investigating specific domestic violence interventions to improve outcomes for psychiatric patients (Howard 2010b). Moreover, there is some evidence to suggest that patients with severe mental illness may find it difficult to access services from the domestic violence sector (Howard 2010b). Nevertheless, information about local domestic violence services should be made available to psychiatric patients and should be displayed in public and private areas, such as toilets.

\section{Independent domestic violence advisors}

Developments in the domestic violence sector include accreditation for independent domestic violence advisors or IDVAs (www.caada.org.uk/ practitioner_resources/IDVAresources.htm). They are highly trained to carry out risk assessments, offer safety planning and legal advice, and provide practical and emotional support, with signposting to other agencies when needed and referral of high-risk patients to multi-agency risk assessment conferences (MARACs). There are some differences in service provision in Scotland and Northern Ireland, but MARACs involving the domestic violence sector are found in Glasgow and in Northern Ireland. Evaluations of independent domestic violence advisor services suggest that they are both effective and costeffective (Howarth 2009), although randomised controlled trials have not been carried out. Mental healthcare organisations should therefore develop care pathways in collaboration with local domestic violence services, so that mental health professionals can work with the domestic violence sector when appropriate.

\section{Multi-agency risk-assessment conferences}

A MARAC is a police-led meeting (though not police-led outside of England and Wales) in which information is shared on very high-risk domestic abuse patients. They are attended by representatives of local police, probation, health, child protection, housing practitioners, independent domestic violence advisors and other specialists from the statutory and voluntary sectors. Non-criminal justice agencies need to be well represented at these conferences. The perspective of mental health professionals will be different from that of the police or probation service, which typically are aware of criminal incidents only, the perpetrator's history and the presence of other aggravating factors, such as drugs or weapons.

After sharing all of the relevant information that they have about a victim, the representatives discuss options for increasing the safety of the victim and turn these into a coordinated action plan. The primary focus of the MARAC is to safeguard the adult victim. The conference will also make links with other fora to safeguard children and manage the behaviour of the perpetrator. At the heart of the conference is the working assumption that no single agency or individual can see the complete picture of the life of a victim, but all may have insights that are crucial to their safety. The victim does not attend the meeting but is represented by an independent domestic violence advisor who speaks on their behalf (www.caada.org.uk/ practitioner_resources/MARACresources.htm).

The first MARAC took place in Cardiff, UK, in 2003 and evaluations have found that their use reduces recidivism, even for the highest risk patients (Robinson 2005), and improves professionals' practice and the safety of victims and their children (Robinson 2004). There are now increasing numbers of these conferences across the UK, seeing large numbers of high-risk patients (for example, there were 300 multi-agency risk assessment conferences in the south London borough of Lambeth in 2009).

\section{Conclusions}

Domestic violence is strongly associated with mental disorders, but mental health professionals underdetect domestic violence (Box 5). Health policy makers are therefore introducing routine enquiry into psychiatric services. There is a limited evidence base on the effectiveness of routine enquiry in improving health outcomes, but studies suggest that it will be optimally effective if mental healthcare professionals are trained in how to ask about domestic violence safely, understand the nature of domestic violence and are able to support victims, including by appropriate referral to domestic violence services and multi-agency risk assessment conferences. Systematic training, policy and the development of local partnerships should precede changes in 


\section{B0X 5 Key points}

- Domestic violence is as serious a cause of death and incapacity among women aged $15-49$ as cancer

- There is a strong association between domestic violence and mental health problems but a very limited evidence base on interventions to address this violence and its consequences

\section{Future directions}

- Future controlled studies are needed to evaluate the prevalence of domestic violence experienced by men and women with severe mental illness

- Evidence on safe and effective interventions, particularly for people with severe mental illness, will help mental healthcare professionals to deliver more appropriate care for their patients

healthcare professionals' practice to provide an integrated response. Further research to increase the evidence base on interventions is needed, particularly with regard to interventions for people with severe mental illness.

\section{Acknowledgements}

I would like to thank the anonymous reviewer for the very thoughtful and helpful comments.

\section{References}

Alhabib S, Nur U, Jones R (2010) Domestic violence against women. Systematic review of prevalence studies. Journal of Family Violence 25 : 369-82.

American Psychiatric Association (1994) Diagnostic and Statistical Manual of Mental Disorders (4th edn) (DSM-IV). APA.

Bacchus L, Aston G, Torres Vitolas C, et al (2009) A Theory-Based Evaluation of a Multi-Agency Domestic Violence Service Based in maternity and Genitourinary Services at Guy's \& St Thomas' NHS Foundation Trust. King's College London.

Campbell JC (2002) Health consequences of intimate partner violence. Lancet 359: 1331-5.

Campbell JC, Lewandowski LA (1997) Mental and physical health effects of intimate partner violence on women and children. Psychiatric Clinics of North America 20: 353-74.

Cloitre M, Stovall-McClough KC, Nooner K, et al (2010) Treatment for PTSD related to childhood abuse. A randomized controlled trial. American Journal of Psychiatry 167: 915-24.

Coleman K, Jansson K, Kaiza P, et al (2007) Homicides, Firearm Offences and Intimate Violence 2005/2006. Supplementary Volume 1 to Crime in England and Wales 2005/2006. Home Office Statistical Bulletin 02/07. Office for National Statistics.

Department of Health (2000) Domestic Violence. A Resource Manual for Health Professionals. Department of Health.

Department of Health (2008) Refocusing the Care Programme Approach. Policy and Positive Practice Guidance. Department of Health.

Department of Health (2010) The Report from the Taskforce on the Health Aspects of Violence Against Women and Children. Department of Health.

Feder GS, Ramsay J, Dunne D, et al (2009) How far does screening women for domestic (partner) violence in different health-care settings meet criteria for a screening programme? Systematic reviews of nine UK National Screening Committee criteria. Health Technology Assessment 16.

Garcia-Moreno C, Jansen HA, Ellsberg M, et al (2006) Prevalence of intimate partner violence. Findings from the WHO multi-country study on women's health and domestic violence. Lancet 368: 1260-9.

Gazmararian JA, Petersen R, Spitz AM, et al (2000) Violence and reproductive health. Current knowledge and future research directions. Maternal \& Child Health Journal 4: 79-84.

Golding JM (1999) Intimate partner violence as a risk factor for mental disorders. A meta-analysis. Journal of Family Violence 14: 99-132.

Greenwood GL, Relf MV, Huang B, et al (2002) Battering victimization among a probability-based sample of men who have sex with men. American Journal of Public Health 92: 1964-9.

Hegarty K, Taft A, Feder G (2008) Violence between intimate partners. Working with the whole family. BMJ 337: a839.

Herman J (2001) Trauma and Recovery. From Domestic Abuse to Political Terror. Rivers Oram/Pandora.

Hester M, Donovan C (2009) Researching domestic violence in same-sex relationships. A feminist epistemological approach to survey development. Journal of Lesbian Studies 13: 161-73.

Home Office (2010) Violence: domestic violence. Home Office (http:// webarchive.nationalarchives.gov.uk/20110218135832/http://rds. homeoffice.gov.uk/rds/violencewomen.html).

Howard LM, Trevillion K, Khalifeh H, et al (2010a) Domestic violence and severe psychiatric disorders. Prevalence and interventions. Psychological Medicine 40: 881-93.

Howard LM, Trevillion K, Agnew-Davies R (2010b) Domestic violence and mental health. International Review of Psychiatry 22: 525-34.

Howarth E, Stimpson L, Barran D, et al (2009) Safety in Numbers: A MultiSite Evaluation of Independent Domestic Violence Advisor Services. Henry Smith Charity.

Jones L, Hughes M, Unterstaller U (2001) Post-traumatic stress disorder (PTSD) in victims of domestic violence. A review of the research. Trauma, Violence \& Abuse 2: 99-119.

Khalifeh H, Dean K (2010) Gender and violence against people with severe mental illness. International Review of Psychiatry 22: 535-46.

Lewis G (2007) Saving Mothers' Lives. Reviewing Maternal Deaths to Make Motherhood Safer 2003-2005. The Seventh Report on Confidential Enquiries into Maternal Deaths in the United Kingdom. CEMACH.

Ludermir AB, Lewis G, Valongueiro SA, et al (2010) Violence against women by their intimate partner during pregnancy and postnatal depression. A prospective cohort study. Lancet 376: 903-10.

Morgan JF, Zolese G, McNulty J, et al (2010) Domestic violence among female psychiatric patients: cross-sectional survey. Psychiatrist 34 : $461-4$.

National Collaborating Centre for Mental Health (2005) Post Traumatic Stress Disorder (PTSD): The Management of Adults and Children in Primary and Secondary Care (Clinical Guideline 26). National Institute for Health and Clinical Excellence.

Povey D (2004) Crime in England and Wales 2002/2003. Supplementary Volume 1. Homicide and Gun Crime. Office for National Statistics.

Read J, Fraser A (1998) Abuse histories of psychiatric inpatients. To ask or not to ask? Psychiatric Services 49: 355-9.

Robinson AL (2004) Domestic Violence MARACs for Very HighRisk Victims in Cardiff. A Process and Outcome Evaluation. Cardiff University.

Robinson AL, Tregidga J (2005) Domestic Violence MARACs (MultiAgency Risk Assessment Conferences) for Very High-Risk Victims in Cardiff, Wales. Views from the Victims. Cardiff University.

Rose D, Trevillion K, Woodall A, et al (2011) Barriers and facilitators of disclosures of domestic violence by mental health service users: qualitative study. British Journal of Psychiatry 198: 189-94.

Sharhabani-Arzy R, Amir M, Kotler M, et al (2003) The toll of domestic violence. PTSD among battered women in an Israeli sample. Journal of Interpersonal Violence 18: 1335-46.
MCO answers

1 a $\quad 2$ e $\quad 3$ a $\quad 4 b \quad 5 d$ 
Sullivan CM, Bybee DI (1999) Reducing violence using community-based advocacy for women with abusive partners. Journal of Consulting and Clinical Psychology 67: 43-53.

Walby S, Allen J (2004) Domestic Violence, Sexual Assault and Stalking. Findings from the British Crime Survey. Home Office Research Study 276. Home Office Research, Development and Statistics Directorate.
Walby S (2009) The Cost of Domestic Violence. Women and Equality Unit.

Wathen CN, MacMillan HL (2003) Interventions for violence against women. Scientific review. JAMA 289: 589-600.

Yearnshire S (1997) Analysis of cohort. In Violence Against Women (eds S Bewley, J Friend, G Mezey). RCOG Press.

\section{MCQs}

Select the single best option for each question stem

1 The strongest single risk factor for experiencing severe domestic violence is:

a female gender

$\mathrm{b}$ age less than 30

c partner misuses alcohol/drugs

$d$ family history of abuse

e socioeconomic deprivation.

2 The following statement is true:

a 25000 children witness domestic violence in their homes each year in England and Wales

b $20 \%$ of male homicide victims are killed by a partner/ex-partner

c pregnancy is usually associated with a decrease in violence

$\mathrm{d}$ domestic violence is the leading cause of maternal deaths in the perinatal period

e two women are killed by a partner or ex-partner each week in England and Wales.
3 It is true that:

a patients who have experienced domestic violence are at a greater risk of injury when they leave the relationship

b strangulation injuries are rare in victims of domestic violence

c referral to a multi-agency risk-assessment conference should be routine for all cases of domestic violence

d reasons for concern about domestic violence should not be included in a patient's medical record if she does not disclose violence

e domestic violence is not associated with psychotic disorders

4 The following is not good clinical practice:

a routine enquiry about domestic violence

b provision of information after disclosure for all victims to take home

c safety assessment by mental health professionals d referral to a refuge for woman at a high risk of serious injury

e always seeing women with partners for assessments.

5 A multi-agency risk-assessment conference is:

a attended by the victim of domestic violence

b relevant for all cases of domestic violence

c always police-led

d should be attended by a mental health professional

$e$ is only carried out where there are child protection concerns.

\section{IN OTHER Extract from $A$ Guard Within, by Sarah Ferguson} WORDS

\section{Selected by Femi Oyebode}

Sarah Ferguson wrote an intensely moving account of her experience of psychoanalysis following the sudden and unexpected death of her psychoanalyst before the end of her treatment. This excerpt is from her book $A$ Guard Within, published by Chatto \& Windus, 1973. Reprinted by permission of The Random House Group Limited.

doi: 10.1192/apt.18.2.136
You did die. We talked so often of your dying, and you were determined not to, not just yet. But you did die. Nearly four months ago, and I still cannot believe it. Most people do not want to talk about death and mourning. I want to talk of it all the time because you are the person who I have loved the most, and you have died. I know all about the outer world of social responsibility, so no one can accuse me of continuing to grieve for you. You did not wish to leave your wife and your daughter and your brother, and some of your colleagues and friends. You did not wish to leave me either, and I do not know how to live without you. You knew it would be so. 